\title{
METHODOLOGY OF DESIGN AND VALIDATION OF THE SHOP FLOOR MILLRUN METHOD
}

\author{
Michal Šimon, Josef Babor, Michal Bochinský \& Pavel Kábele
}
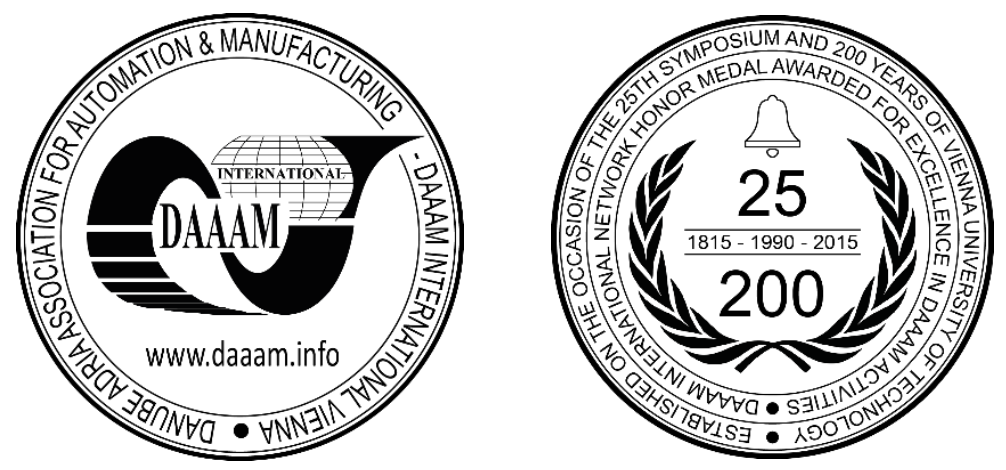

This Publication has to be referred as: Simon, M[ichal]; Babor, J[osef]; Bochinsky, M[ichal] \& Kabele, P[avel] (2017). Methodology of Design and Validation of the Shop floor Millrun method, Proceedings of the 28th DAAAM International Symposium, pp.1143-1150, B. Katalinic (Ed.), Published by DAAAM International, ISBN 978-3-902734-11-2, ISSN 1726-9679, Vienna, Austria

DOI: $10.2507 / 28$ th.daaam.proceedings.159

\begin{abstract}
This article discusses a methodology that is used to set the appropriate material feed rate using the Millrun method. The methodology uses basic calculations and data about products, warehousing technology. Basic data used in this methodology are static and also the simulation of Millrun is static. This methodology using basic data as an input and provides four determined steps leading to successful Millrun implementation. Methodology uses only one type of vehicle for supplying. Methodology is made as easy as it can be to ensure applicability for everyone and requires personal approach to solutions based on common sense in rationalization of the process. Methodology aims to provide a sequence of steps leading to implementation of shop-floor Millrun.
\end{abstract}

Keywords: Millrun; shop-floor; implementation; lean logistics; pull system

\section{Introduction}

Current state of industrial companies is focusing on reduction of cost by rationalization. Achievement of cost reduction is conditional to implementation of more effective processes.

If the companies want to do so, they need to have easy to use, straightforward methodologies based on skilled people, methodologies robust enough to be easily and quickly implemented into production or logistics.

The Milk run system or method is not a novelty today. It originates in the early 20th century, where its essence consisted of regular sips of fresh milk from individual farmers, for example, to a Milkrunner. The family could rely on the fact that empty bottles would be replaced for full ones at the set time.

The correct setting of the Millrun system is a tricky task and a lot of effort is needed. [3] 


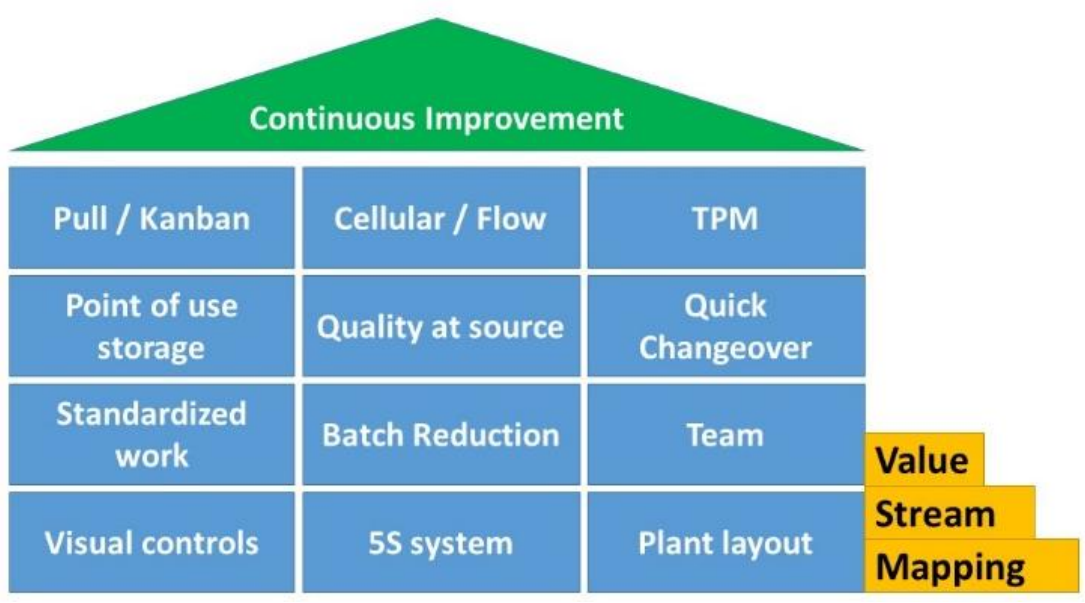

Fig. 1. Pillars of lean manufacturing [4]

In the case study described in this article, a focus was placed on the already established Milk run system, which supplied the production on one assembly line and the accompanying workplaces. The pull system as such is one of the basic pillars of lean manufacturing, and this fact is shown in Figure 1. Generally, setting up the efficient functioning of the Milk run is a complex process that is very demanding, and it is necessary to solve all the modifications together with the logistics, lean and purchasing departments. However, even the loading pull system with a Milk run can be problematic and have problems. In addition to problems such as the fact that the operator loses the Kanban card, takes the wrong amount, does not notice the Kanban cards, etc., the train for the Milk run circuit may be overloaded or unloaded. One of the issues that need to be tackled may be the case solved in this case study. There was a Milk run in the company that suffered from the problem that there was an irregular accumulation of a great deal of material loading requirements in such a way that the trainer would have to load much more material than he would be physically and physically capable. There are several possible causes of this problem, so it was necessary to carry out analyzes to identify the root cause of the problem. This article gives an insight into the methodology that leads to the supply system settings using a static simulation. [1], [2]

There is a lot of papers written about implementation of Millrun method but most of these papers focus on setting up the Millrun routing as vehicle routing problem (VRP). [5] Toshinori Nnemeto [6] write about JIT concept on the assembling line and also created mathematical model to help in station demand modelling. This paper issued the number of Kanban cards in the stock. The paper development and appl. Of milk run distribution system in express industry based on saving algorithm [7] reviewed Millrun scheme can help to find shortest distance and lowest cost, but also there is problem, that they are solving just a shortest road and not a Millrun system as one unit. Paper [7] also provides information Millrun can improve the load factor, advance time efficiency, environment and time constrains are discussed too.

This paper uses Simplified steps of supply procurement planning process [8]. These steps are Volume calculation Master road planning - Supplier negotiations - Master road revision - Dock scheduling - Daily route planning, but just in few steps and goes deeper into simplification of steps and more precisely defines each step to ensure applicability for other companies. Kopeček [9] made the conclusion that too sophisticated methods mostly fail due to the inaccuracy of the input data. This inaccuracy is more caused by dynamic changes in this process and its development in time than by insufficient quality of work in technical preparation of the production, inaccurate observations and measuring in the production process. Because of this, research and development activities have been focused more on simple and robust methods of optimization which could be both easier in implementation and resistant to changes of parameters of optimized systems.

Limitations of this paper are using of one type of supplying vehicle, multiple kinds of storage systems, unchanging train road (train is always using one road which does not change from the lap to lap) and stability of process (same process which does not change from lap to lap).

\section{Methodology}

The Milk run system setup methodology consists of the 4 steps that are depicted in Figure 2. Each of these steps is further discussed in the individual chapters of this article.

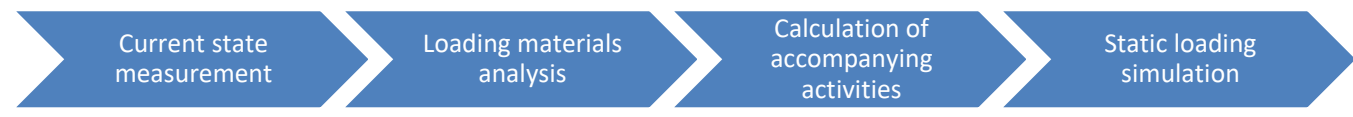

Fig. 2. Basic points of the methodology 


\subsection{Current state measurement}

The methodology is different in the first step, depending on whether the Milk run method is already in place in the company, or whether this methodology is used to design a future state. If the Milk run loading system is already introduced in the company, it is advisable to measure the current supply system as a first step.

In essence, if the Milk run supply system is not implemented in the company, the first step of the methodology is skipped and the second step is carried out.

The basic idea behind this step of the methodology is to find out how the already implemented Milk run system works / does not work. It is also possible at this stage to identify potential waste in the supply system and it is also a step that makes it possible to design further improvements in addition to changes in the supply system.

The first step is to measure the current state by performing snapshots of an individual working day, more precisely, a Milkrunner. Ideally, at this step, it is advisable to measure all Milkrunner activities during work shift, so that measurements can be made on several shift focused on different Milkrunners and in a combination of shifts (morning, afternoon, night). Within the measurement it is necessary to pay attention not only to how long the activity takes, but also how many transport units are handled, what warehouse, what warehouse technology, based on what storage principle the material is handled and what all the activities are carried out during the loading. In this way, it is possible to record all processes and times for the current state. However, in this step it is also necessary to record the route that the trains run through the spaghetti diagram.

Subsequently, the measurement results should be analyzed to obtain information on all the trajectories traveled by the trains, how many transport units are loaded on average in that round, what is the difference between the loaded and unloaded packaging units (quantity) and how long did the loading cycle take.

\subsection{Current state measurement}

The second step of this methodology is the same if the Milk run system is already implemented and also if the Milk run system is not implemented yet. As can be seen from the title of this step, this is an analysis of loading materials. More specifically, it is necessary to determine which materials are or will be loaded by the Milk run method. An ABC-XYZ analysis, which clearly defines what material is to be loaded by the loading method, can be used to identify these materials. However, it always depends on the total quantity of materials in circulation and what other methods of loading are used in the company. After selecting materials that are or will be loaded by the Milk run method, it is necessary to get the basic data for further work with the data and these are

- Monthly material consumption (ideally for one or more years)

- Yearly material consumption

- Possibly line tact and composition of production (BOMs, decompositions, composition of annual production, etc.)

- Number of pieces in one storage unit

- Type of storage unit (KLT, pallet, freely, etc.)

- $\quad$ Place of material storage

- Type of technology used for storage (lift system, catch shelf, pallet rack, etc.)

From this data, the hourly consumption of the material is calculated based on monthly material consumption:

$$
\text { Average hourly consumption }=\frac{\text { Monthly consumption }(\mathrm{pcs})}{\text { Shift time } * \text { Number of shifts per month }}
$$

This calculates the values for all the available months and searches for fluctuations in the consumption of the material. If there are no fluctuations in consumption, there is no problem. If material consumption fluctuations are recorded, it is appropriate to continue to calculate the highest value for the consumption of the material, but only after checking the proportion to the average material consumption.

It is also appropriate to compare the average hourly consumption of material from the monthly consumption to the average hourly consumption of the annual material consumption.

$$
\text { Average hourly consumption }=\frac{\text { Annual consumption }(p c s)}{\text { Shift time } * \text { Number of shifts per year }}
$$

From the other data listed at the beginning of this chapter, data on the quantity of pieces in a single storage unit is used to calculate the processing time for a single storage unit. Basically, it's a simple calculation:

$$
\text { The value of holding a package (hours) }=\frac{\text { Package size }(\mathrm{pcs})}{\text { Average consumption }\left(\frac{\mathrm{pcs}}{\text { hour }}\right)}
$$


Other data will primarily be used for further calculations. However, it is still appropriate to compare the consumption of monthly and annual data with data on consumption based on the line tact:

$$
\text { Hourly consumption }=\left(\frac{3600}{\text { Time for } 1 \mathrm{pc}}\right) * \text { Pcs per } 1 \text { product }
$$

The main output of this step is to determine the average time consumption of a storage unit of monthly consumption and to associate information about the type of storage unit, the storage location of the material and the type of technology used for storage.

\subsection{Calculation of accompanying activities}

In this step, it is possible to use the data from step 1 to rationalize the current loading or the MOST method to determine the times of the partial and accompanying loading activities. The best way to define what this time is about is by using the following formula, which is further used as the simulation output:

$$
t_{k}=t_{\text {pick }}+t_{\text {unload }}+t_{\text {load }}+t_{\text {ride }}
$$

$t_{k}$ - Total lap time for one load cycle in minutes

$\mathrm{t}_{\text {pick }}$ - The time required to pick up the material from the warehouse in minutes

$\mathrm{t}_{\mathrm{unload}}$ - The time required for the removal of material in production at workplaces

$\mathrm{t}_{\text {load }}$ - The time required to store empty packaging in the production in minutes

$\mathrm{t}_{\text {ride }}$ - Train time in minutes

Now for the calculation of the accompanying activities - it is more precisely the picking time, the loading time, the unloading time that is related to one transport unit. The relationship to one transport unit is necessary for further work with these data in static simulation. Another accompanying time is the ride time of a train, which is logically not related to a single transport unit, but to a single round. As already explained in the introduction to this chapter, it is necessary to analyze the measurement results and possibly use the MOST method to determine the partial times for

- Time for pick - This value must be related to the type of packaging unit and the storage technology. If the material is picked from the vertical lift system, the time is different from when the material is picked from the drop shelf. It also takes a different time to remove one palette and pick up KLT, which is logical information. Time includes finding the material, picking up and putting the material into the train.

- Unloading time is the time that involves getting off from the train at the production line, picking up the material from the train, and placing the material in the storage position at the workplace.

- The loading time includes grabbing the empty storage unit and placing the unit on the train.

- Train travel time includes the total time of the train journey from the exit from the warehouse to the whole cycle and re-exit. This time can no longer be acquired through the MOST method, but it is possible to use the time form measurement (if the circuit is well set). If it is not well set up, it must be designed just like designing a new Milk run supply system by applying the route to the layout (the total transport distance is determined) and the conversion from the average speed of the train is used, however, it is necessary to not use the speed of the train from the train manufacturer's catalog, but reduce the speed to approximately half (turning, accelerating, braking, etc.) According to current information and measurement it is advisable to use a speed of about 3-5 m/s.

\subsection{Calculation of accompanying activities}

The static simulation must be done separately for each type of storage technology in combination with the type of storage unit. The materials are separated according to this combination and the following procedure is used:

- Enter the identification numbers and materials names horizontally into the first two lines.

- Insertion of the hourly hold value of one package of the material under the concrete material type.

- The times are also generated when the material is reprocessed, always taking into account the total simulated time (the minimum time to be generated for the fastest consumer must be greater than the time of the last simulated round).

In this way, a time axis that will show the total consumption of all materials for a given combination of storage technology and storage unit, is generated, see Figure 3, where $\mathrm{X}$ indicates the consumption time of one package for material one, and $\mathrm{Y}$ denotes the consumption time of one package for material 2. The visualization for all other materials would look the same way. 


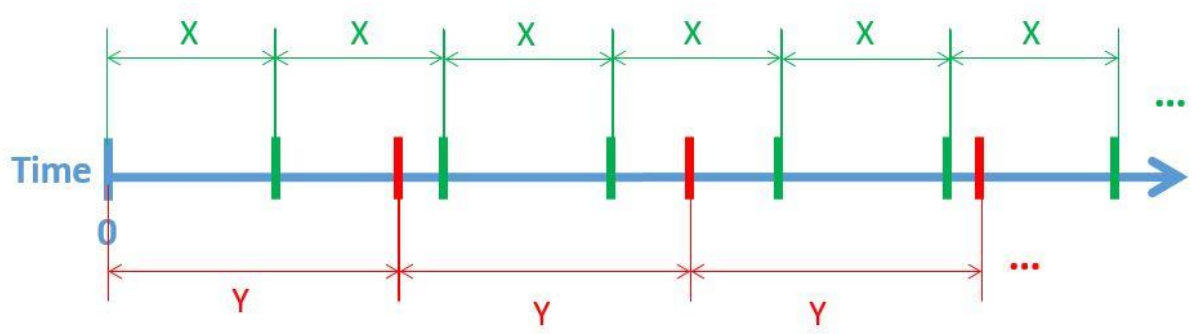

Fig. 3. Visualization of consumption

After generating these all occurrence times, it is necessary to sum up the number of packaging units in one round by creating a table of times indicating the beginning and end of one scheduled round (ideally referring to one cell that recalculates all values when the change occurs). See the example in Table 4.

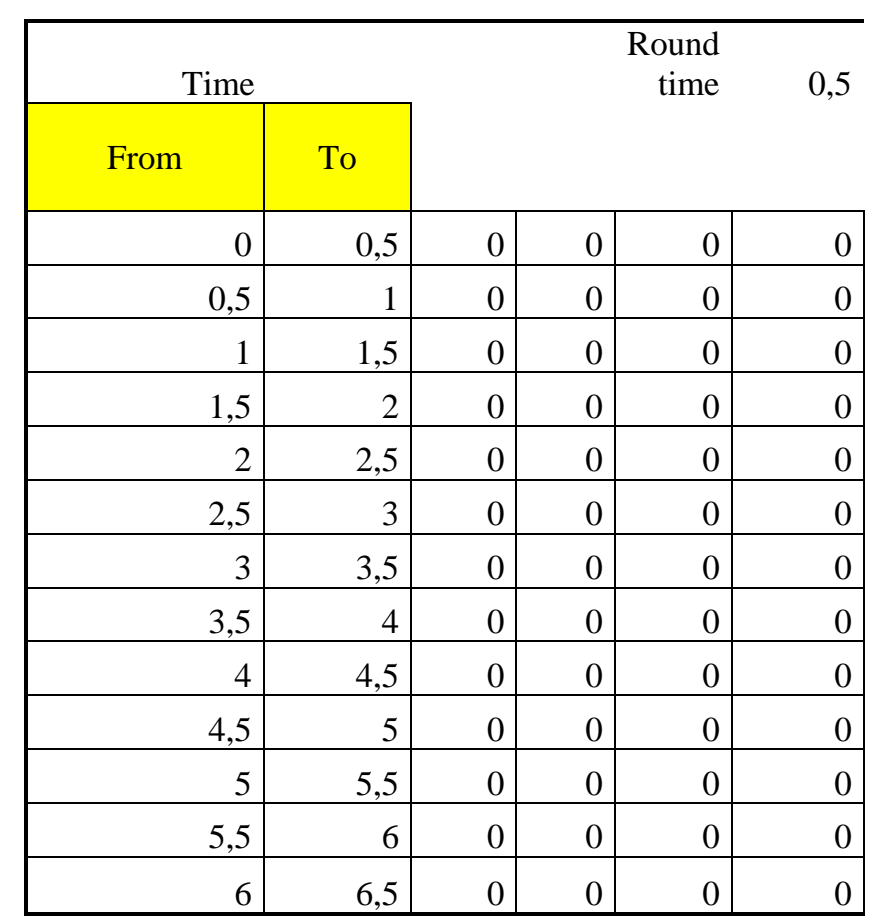

Table 1. Simulation example

From these basic data, countif function will then determine how many materials will be processed in a given timeframe. More specifically, the function may look as follows:

\section{(=COUNTIFS(C\$4:C\$841;">="\&\$A850;C\$4:C\$841; "<"\&\$B850)}

If we then add up the number of simulated packaging units in the round, so we can proceed with the calculation of one round time, which is actually a combination of all of the data from step 3 and 4 . The basic formula for calculating the round time is still:

When:

$$
t_{k}=t_{\text {pick }}+t_{\text {unload }}+t_{\text {load }}+t_{\text {ride }}
$$

$$
t_{\text {pick }}=\sum_{i=1}^{n} \text { time for pick }_{i} * S K U \text { s in round }
$$

In which is $\mathrm{i}=$ the type of storage units in storage technology, and $\mathrm{n}$ is the total number of combinations of storage unit and technology. However, the picking time must be taken from the values of the number of packing units in the round preceding the values in the other quantities.

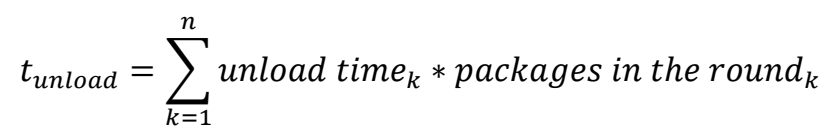


In which $\mathrm{k}=$ given type of storage unit and $\mathrm{n}$ is the total number of types of storage units.

$$
t_{\text {load }}=\sum_{k=1}^{n}{\text { load } \text { time }_{k} * \text { packages in the round }}_{k}
$$

The ride time is the same for each round and the calculation method is in the previous chapter. In this way, it is appropriate to generate a sufficient number of occurrences so that at least twice the spin of the most slowly consumed material occurs. As a result, the end result is a histogram showing the frequency of occurrence of each round time - an output that uniquely determines whether it will be possible to prosecute the line loading in a combination of materials, processes and all possible aspects affecting the supply, is created.

\section{Case study}

The case study is based on the described methodology and for this reason only the outputs of the individual steps of the methodology will be discussed.

$1^{\text {st }}$ step Current state measurement

From the measurement of the current state it appeared that the different workers are traveling in a different way, the exact timetable is not specified, the ordering of the material in the electronic ordering system is not working correctly, the ordering frequency of the material is higher at the beginning and at the end of the shift and there is the wrong storage of some KLT.

\begin{tabular}{|c|c|c|c|c|c|c|c|c|c|}
\hline \multicolumn{10}{|c|}{ Time with ride } \\
\hline Round & $\begin{array}{l}\text { Number od } \\
\text { picked SKUs } \\
\text { empty }\end{array}$ & $\begin{array}{l}\text { Picked } \\
\text { SKUs } \\
\end{array}$ & $\begin{array}{l}\text { Supplied } \\
\text { SKUs }\end{array}$ & Picking & \begin{tabular}{|l|} 
Picking + \\
kardex \\
picking \\
\end{tabular} & $\begin{array}{l}\text { Clean ride } \\
\text { time }\end{array}$ & Round & $\begin{array}{l}\text { Start } \\
\text { time }\end{array}$ & $\begin{array}{l}\text { End } \\
\text { time } \\
\end{array}$ \\
\hline 1 & 16 & 8 & 6 & 0:02:46 & 0:07:48 & 0:08:20 & 00:17:52 & 08:25:06 & 08:42:58 \\
\hline 2 & 14 & 6 & 7 & 0:01:17 & 0:01:17 & 0:01:08 & 00:07:41 & 08:42:58 & 08:50:39 \\
\hline 3 & 32 & 17 & 19 & 0:06:59 & $0: 24: 50$ & 0:20:03 & 00:38:02 & 08:50:39 & 09:28:41 \\
\hline 4 & 14 & 31 & 31 & $0: 19: 28$ & $0: 33: 36$ & $0: 37: 23$ & 01:06:09 & 09:28:41 & 10:34:50 \\
\hline 5 & 31 & 17 & 20 & 0:03:07 & 0:15:09 & $0: 12: 16$ & $00: 32: 55$ & \begin{tabular}{|l|}
$10: 34: 50$ \\
\end{tabular} & 11:07:45 \\
\hline 6 & 13 & 20 & 18 & 0:08:42 & 0:23:12 & 0:21:57 & 01:24:57 & 11:07:45 & 12:32:42 \\
\hline 7 & 37 & 16 & 20 & 0:06:35 & $0: 19: 46$ & 0:28:04 & 01:22:28 & 12:32:42 & 13:55:10 \\
\hline 8 & 31 & 15 & 14 & 0:21:00 & $0: 36: 46$ & $0: 42: 26$ & 01:09:10 & 13:55:10 & 15:04:20 \\
\hline Suma & 188 & 130 & 135 & 1:09:54 & 2:42:24 & 2:51:37 & $6: 39: 14$ & & \\
\hline
\end{tabular}

Table 2. Demonstration of measurement outputs

$2^{\text {nd }}$ step Loading materials analysis

The materials for the Milk run have been identified in the company, so analyzes needed for further data processing have been performed. The company also used 3 warehouse technologies and one kind of handling unit.

\begin{tabular}{|l|r|r|r|r|r|r|l|l|}
\hline Part number & $\begin{array}{c}\text { Consumption } \\
\text { / year }\end{array}$ & $\begin{array}{c}\text { Consumption } \\
\text { / mounth }\end{array}$ & $\begin{array}{c}\text { Bas } \\
\text { unit } \\
\text { Compsumt } \\
\text { ion / year } \\
\text { Avrg. }\end{array}$ & $\begin{array}{c}\text { Avrg. } \\
\text { ompsumti } \\
\text { onounth }\end{array}$ & $\begin{array}{c}\text { Compsumtion } \\
\text { / tact }\end{array}$ & $\begin{array}{c}\text { Pieces } \\
\text { in SKU }\end{array}$ & $\begin{array}{c}\text { Turn over } \\
\text { time }\end{array}$ \\
\hline 0009145814 & 28000,000 & 2333,333 & ST & 8,889 & 7,778 & 1,579 & 7000 & 7,778 \\
\hline 0009381980 & 5905,832 & 738,229 & ST & 1,875 & 2,461 & 3,158 & 6000 & 2,461 \\
\hline 0009073317 & 2776,044 & 347,006 & ST & 0,881 & 1,157 & 3,158 & 5000 & 1,157 \\
\hline 0009145614 & 8912,000 & 742,667 & ST & 2,829 & 2,476 & 1,579 & 4400 & 2,476 \\
\hline 9292003012 & 21210,604 & 2651,326 & ST & 6,734 & 8,838 & 1,579 & 4000 & 8,838 \\
\hline
\end{tabular}




\begin{tabular}{|l|r|r|l|l|l|l|l|l|}
\hline 7777700906 & 20154,224 & 2519,278 & ST & 6,398 & 8,398 & 3,158 & 4000 & 8,398 \\
\hline 0009073315 & 7467,481 & 933,435 & ST & 2,371 & 3,111 & 1,579 & 3200 & 3,111 \\
\hline 0009642111 & 332,000 & 110,667 & ST & 0,105 & 0,369 & 6,316 & 3000 & 0,369 \\
\hline 9062316126 & 3180,918 & 397,615 & ST & 1,010 & 1,325 & 3,158 & 3000 & 1,325 \\
\hline 1909146510 & $-2592,000$ & $-216,000$ & ST & 0,823 & 0,720 & 1,579 & 3000 & 0,720 \\
\hline 0009643709 & 7089,804 & 886,226 & ST & 2,251 & 2,954 & 3,158 & 2400 & 2,954 \\
\hline 0009552037 & 44000,000 & 3666,667 & ST & 13,968 & 12,222 & 1,579 & 2000 & 12,222 \\
\hline 7914990928 & 2495,788 & 311,974 & ST & 0,792 & 1,040 & 6,316 & 2000 & 1,040 \\
\hline
\end{tabular}

Table 3. Sample data analysis

$3^{\text {rd }}$ step Calculation of accompanying activities

According to the third step, it was determined on the basis of measurements that the times of the individual activities were, Time for pick - 8 seconds per the supermarket, 44 seconds per the cardex and 37 seconds per the virtual cardex. 4 second loading time, 8 second unloading time, Train travel time was determined when designing the route for the shortest route for handling all loaded workplaces

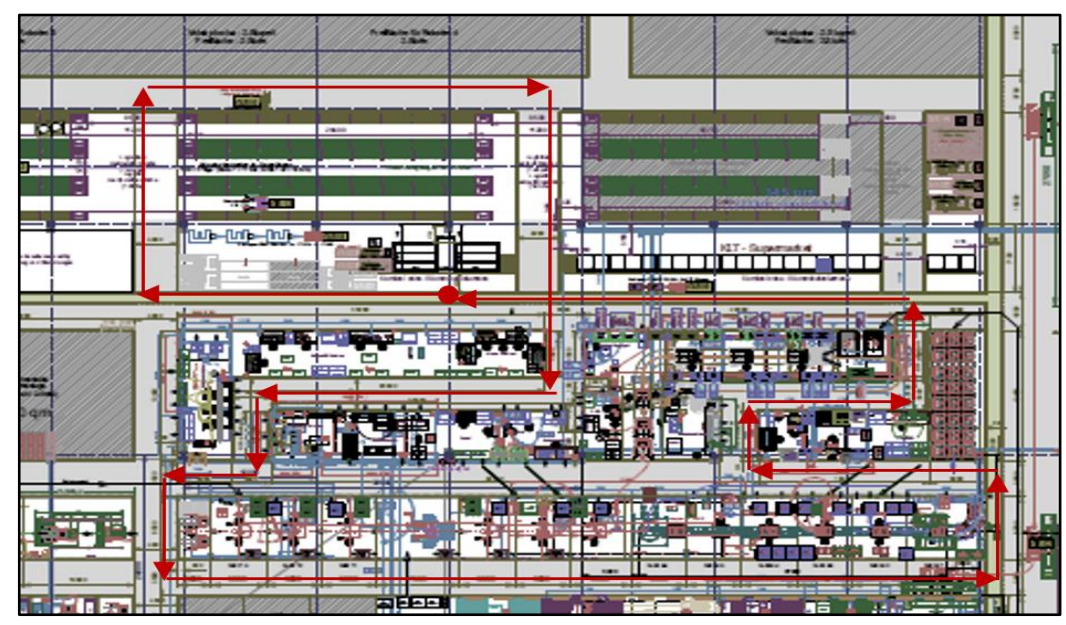

Fig. 4. Designed train route

$4^{\text {th }}$ step Static loading simulation

A static simulation showed that loading would be most convenient every 30 minutes, and the operator should handle all aspects of the cycle. The static simulation outputs have been compared with reality, so that the average amount of loading KLTs was complied with the long-term statistics that the company had processed.

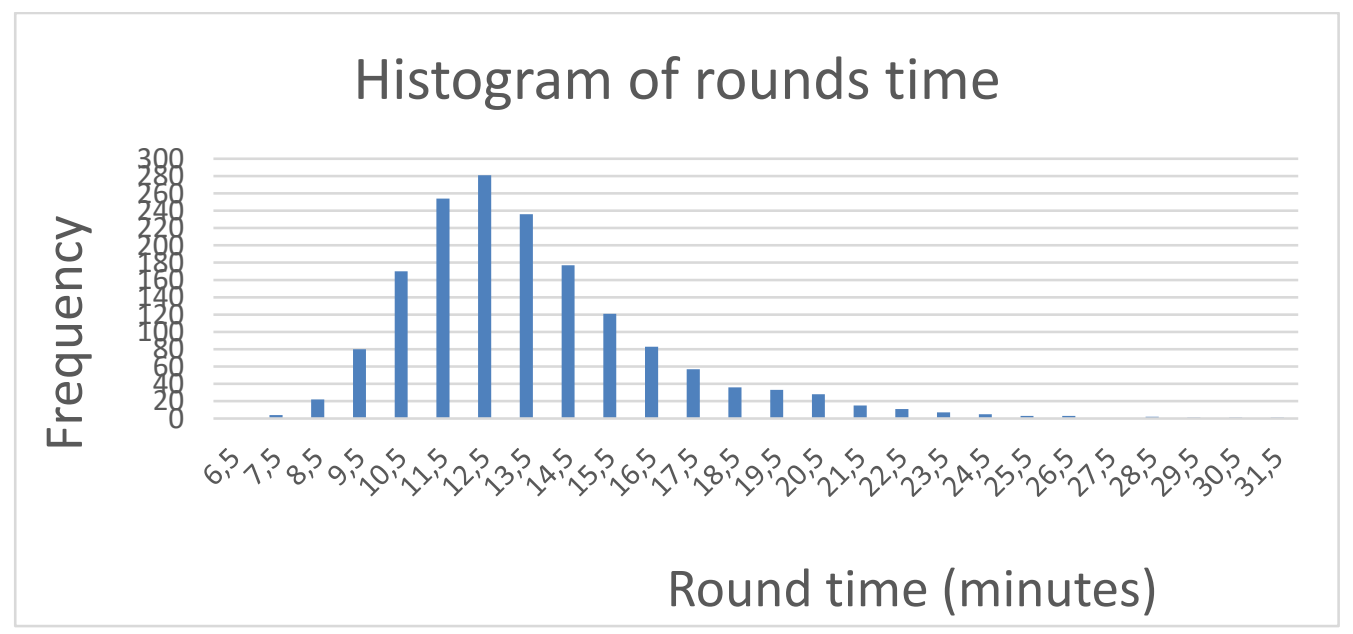

Fig. 5. Histogram of rounds times 


\section{Conclusion}

The problem solved in this paper was uncertainty in setting up the Milkrun supplying system and lack of prediction in setting up the new Milkrun system or evaluation of already implemented Millrun system. Problem have been solved by setting up four step methodology which comes from Measuring current state of the art, Analysis of material supplying, Calculation of accompanying activities and Static Millrun simulation based on MS Excel. The Static simulation is the main part of the whole methodology because it brings prediction for amount of supplying materials.

The case study confirmed that Methodology and static simulation is sufficiently precise for evaluation and setting up. The confirmation is based on number of materials needed to be supplied from Static simulation and real data from company MES system. The Methodology has been used only in two companies so steps for the future are evaluation in larger group of companies and confirmation of generality for using this methodology.

This article describes the methodology that is used to implement and rationalize the Milk run loading system. The methodology consists of 4 basic steps:

$$
\begin{aligned}
& 1^{\text {st }} \text { step-Current state measurement } \\
& 2^{\text {nd }} \text { step - Loading material analysis } \\
& 3^{\text {rd }} \text { step - Calculation of accompanying activities } \\
& 4^{\text {th }} \text { step - Static loading simulation }
\end{aligned}
$$

The conclusion of the article was a case study that used this methodology and at the same time confirmed that this methodology was applicable in practice. The outcome of the case study was the rationalization of the current Milk run loading system, and this study helped to identify waste and problems in the supply system on the Time distribution of the mulkrunner workload, Creating a model for continuous control of the Milk run supply functionality in the company, Setting a fixed train timetable, Determining a rationalized trail, Replacement of storage on pallets with a racking shelf, Changing the placement of material in the warehouse, Training train staff and assembly on ordering material and Improvement in an electronic ordering system.

\section{Acknowledgments}

This article was created with the support of the internal grant of the University of West Bohemia, SGS-2015-065 entitled Development of Sustainable Production System Parameters.

\section{References}

[1] Šimon, M., Troblová, P., (2005), Logistics of the products in the net businnes Proceeding of the 4th DAAAM international conference on advance technologies for developing countries, ISBN: 953-6048-29-9

[2] Edl, M., Kudrna, J., (2013), Methods of industrial engineering . 1. vyd. Pilsen : Smart Motion, s.r.o., ISBN: 978-8087539-40-8

[3] Best industrial [Online], (2016), Available from: http://bestindustrial.cz/clanky/system-milk-run-2/ Accessed: 3 July 2017

[4] citynetevents [Online], (2015) Available from: http://www.citynetevents.com/hanoi/courses/courseimplementation-system-guidance-tpm-total-productive-maintenance-october-19th-2012. Accessed: 8 July 2017

[5] Gyulai, D., (2013), Milk run Vehicle Routing Approach for Shop-floor Logistics, Forty Sixth CIRP Conference on Manufacturing Systems, ISBN: 978-1-62993-594-2

[6] Toshinori nemoto, katsuhiko hayashi, masataka hashimoto, (2010), Milk run logistics by Japanese automobile manufactures in Thailand: procedia social and behavioural sciences 2, ISBN:5980-5989

[7] Zhenlai you and yang jiao(yanshan university china), (2014), Development and appl. Of milk run distribution system in express industry based on saving algorithm:, hindawi publication corp. Mathematical problem appl. Vol.

[8] Theeratham, M., and Lohatepanont, M., (2010) "Vehicle Routing in Milk Run Operations: A Column Generation Based Approach"

[9] Kopeček, P., (2013), Selected Heuristic Methods used in Industrial Engineering, 24th DAAAM International Symposium on Intelligent Manufacturing and Automation, ISSN 1877-7058 